\title{
Lateralized Odontoid in Plain Film Radiography: Sign of Fractures? - A Comparison Study with MDCT
}

\section{Dezentralisation des Dens axis in der Denszielaufnahme als sicheres Zeichen einer Fraktur? Eine Vergleichsstudie mit der Computertomografie}

Authors

Affiliation
S. Keller, K. Bieck, M. Karul, B. Schönnagel, G. Adam, C. Habermann, J. Yamamura

Department of Diagnostic and Interventional Radiology, University Hospital Hamburg Eppendorf, Hamburg, Germany

Key words
spine
trauma
CT
radiography

received 15.2.2015

accepted 11.5.2015

Bibliography

Dol http://dx.doi.org/

10.1055/s-0035-1553237

Published online: 26.6.2015

Fortschr Röntgenstr 2015; 187 :

801-807 @ Georg Thieme

Verlag KG Stuttgart · New York .

ISSN 1438-9029

\section{Correspondence}

\section{Dr. Sarah Keller}

Zentrum für Radiologie und Endoskopie, Klinik und Poliklinik

für Diagnostische und

Interventionelle Radiologie,

Universitätsklinikum

Hamburg-Eppendorf

Martinistr. 52

20255 Hamburg

Germany

Tel.: ++49/178/5566054

Fax: ++ 49/40/7 41056799

s.keller@uke.de

\section{Zusammenfassung \\ $\nabla$}

Ziel: Die Evaluation der Wertigkeit von konventionell-radiologischen Messungen zur Detektion einer Densfraktur im Vergleich zur Schnittbildgebung (CT).

Material und Methoden: 79 Patienten (männlich 31 , weiblich 48 , Alter $60 \pm 26$ Jahre), die aufgrund einer Lateralisation des Dens axis im konventionellen Röntgen (a.p./lat. Projektion und Denszielaufnahme) eine CT-grafische weiterführende Untersuchung der Halswirbelsäule erhielten, wurden ausgewertet. Dabei wurden verschiedene Messparameter wie die atlantodentale Distanz, Winkelmessungen zur Evaluation einer Densangulierung und die Beurteilung des Hinterkantenalignements C0-C3 in den o.g. Projektionen im Vergleich zur CT der HWS als Standard ausgewertet. Die statistische Auswertung zur Beurteilung signifikanter Unterschiede zwischen gesunden Patienten und Patienten mit CT-grafisch gesicherter Densfraktur erfolgte mit dem Discriminatory power Test.

Ergebnisse: 8 von 79 (10,1\%) der untersuchten Patienten wiesen eine Fraktur des Dens axis auf. In 6 Patienten wurde die Fraktur bereits im konventionellen Röntgen gesichert. Weder Messungen der atlantodentalen Distanz (Denszielaufnahme $0,49 \pm 0,13 \mathrm{~cm}$ vs. $0,47 \pm 0,13 \mathrm{~cm}$, lat. $0,16 \pm 0,09 \mathrm{~cm}$ vs. $0,12 \pm 0,09 \mathrm{~cm})$, noch die Winkelmessungen (Denszielaufnahme $87,4 \pm 2,8^{\circ}$ vs. $83,8 \pm 3,5^{\circ}$ lat. $88,5 \pm 6,2^{\circ}$ vs. $88,6 \pm 6,3^{\circ}$ ) oder die Evaluation des Wirbelkörperalignements zeigten signifikante Unterschiede zwischen den gesunden Patienten und den Patienten mit Densfraktur.

Schlussfolgerung: Die Dezentralisierung des Dens axis im konventionellen Röntgen bei Patienten mit Verdacht auf eine Densfraktur ist aufgrund der großen physiologischen Variabilität kein sicheres Zeichen für eine Fraktur. Bei klinischem Verdacht auf eine Densfraktur ist eine native Computertomografie der HWS das Mittel der Wahl.

\section{Abstract \\ $\nabla$}

Purpose: To evaluate X-ray standards for the detection of odontoid fractures. Summary of background data: Cervical spine fractures are a common finding in emergency medicine, accounting for $1-3 \%$ of injuries. Involvement of the $\mathrm{C} 1 / \mathrm{C} 2$ complex is found in $25 \%$ of cases, affecting the odontoid peg in 55-80\%. Regarding the consequences of missed fractures, radiographic techniques built the groundwork for further treatment procedures. As standardized X-ray measurements have not been established, the incidence of unrecognized cervical spine fracture is expected to be up to $20 \%$. The establishment of X-ray-based guidelines is also limited by the presumed low specificity and sensitivity of distance measurements caused by rotational distortion which leads to a rising popularity of $\mathrm{CT}$.

Materials and Methods: 79 (age $60 \pm 26$ yrs) patients with lateralization of the odontoid process on conventional plain film radiography (anteroposterior, lateral, and open mouth odontoid process view projection) were examined. The distance between the odontoid process and lateral mass of $\mathrm{C} 1$, angles of vertical odontoid line and basis of $\mathrm{C} 2$ were measured in the ap view. In the lateral view, dorsal alignment and atlantodental distance were assessed. MDCT examinations were used as a reference. Discriminatory power test was applied to assess significance.

Results: 8/79 (10.1\%) odontoid process fractures were found. Diagnosis was achieved on conventional radiographs in 6 patients. Neither distance and angle measurements between odontoid and C1 nor the dorsal alignment of the vertebral bodies differed significantly between healthy and affected patients.

Conclusion: Decentralization of the odontoid process is not necessarily an indirect sign for its fracture. In patients with suspected injury of the 
Kernaussagen:

- Auch die metrische Evaluation des zervikalen Alignements und der physiologischen Deviation des Dens axis im konventionellen Röntgenbild ermöglicht keinen sicheren Frakturausschluss.

- Bei HWS-Traumata die eine Bildgebung erfordern ist weiterhin ein primäres MDCT indiziert. odontoid process, an MDCT scan might be the method of choice to rule out a fracture.

Key points:

- Due to the wide physiological variety of odontoid process position, even a detailed metric analysis of cervical alignment and odontoid process angulation in X-ray scans is not able to facilitate the diagnosis of odontoid process fractures.

- In the case of cervical spine trauma, which necessitate medical imaging, a primary MDCT scan should be the method of choice. Citation Format:

- Keller S., Bieck K., Karul M. et al. Lateralized Odontoid in Plain Film Radiography: Sign of Fractures? - A Comparison Study with MDCT. Fortschr Röntgenstr 2015; 187: 801-807

\section{Introduction}

$\nabla$

With an overall occurrence of $1-3 \%$ in trauma cases, cervical spine fractures, accounting for up to two-thirds of spinal cord injuries, are a relatively common finding $[1,2]$. Involvement of the C1 / C2 complex is found in $19-25 \%$ of cases, affecting the odontoid peg in $55-80 \%[1,3,4]$. Anderson and D'Alonzo defined three types of odontoid process fractures regarding the fracture location [5]. Type I fractures are considered stable, only affecting the tip of the odontoid process. Types II and III encompass horizontal fractures through the odontoid process, either localized between the level of the transverse ligament and the $\mathrm{C} 2$ vertebral body (type II) or extending into C2 (type III) [5, 6].

Regarding the potentially devastating consequences of missed fractures or disco-ligamentous injuries, radiographic imaging techniques of the upper cervical spine are crucial for injury detection and classification, building the groundwork for further surgical stabilization or non-operative treatment procedures [7 - 9]. Nevertheless, the incidence of delayed or missed diagnosis at the cervical spine in critically injured trauma patients is expected to be relatively high, ranging from 5-20\% [10-12]. One reason might be the lack of generally approved guidelines and protocols for the clinical and radiological assessment of patients suffering cervical spine trauma [13-15]. However, except one method postulated by Carlson et al., measuring the displacement and angulation by drawing lines along the anterior aspect of the dens fragment and C2 body in the lateral cervical radiography or mid sagittal CT reconstruction, radiographic measurement standards for the assessment of angulation or displacement of odontoid fractures have not been established so far [16, 17]. One reason for the lack of standardized X-ray based methods and guidelines might be given by the presumed limited specificity and sensitivity of distance measurements in projection radiography caused by rotational distortion or parallax error, accounting for the rising popularity of computed tomography (CT) scan for trauma evaluation of the upper cervical spine [18 - 22].

Therefore, the aim of our study was to evaluate the finding of odontoid lateralization for the diagnosis of odontoid fractures and to assess whether an additional CT scan can be avoided especially in the light of the rising expenses and radiation exposure associated with this effort.

\section{Materials and Methods}

$\nabla$

\section{Patient population}

79 consecutive cases, which received conventional X-ray scans in lateral and anteroposterior projection upon cervical spine trauma between January 2010 and April 2011, were retrospectively reviewed. All patients $(\mathrm{n}=79)$ underwent multi-detector computed tomography (MDCT) to assess an odontoid process fracture suspected on plain film radiography. Patients under the age of 16 and patients with diagnosed ligament injury in additional performed MRI scans were excluded. Measurement standards for the assessment of odontoid peg lateralization were applied on standard radiographs. The patient's clinical and anamnestic findings upon examination were retrieved from the medical records. The patient cohort undergoing cervical X-ray scan after trauma history was characterized by a mean age of 51.7 years, with a range of 16 to 96 years and gender distribution of 38 men and 60 women. Table 1 summarizes the major clinical characteristics of the patient population.

\section{Radiological Examination - Plain Radiographs}

Patients were examined using a high-end, flat detector direct digital system (Digital Diagnost; Philips, Best, The Netherlands). X-ray imaging of the cervical vertebrae (C $1-7)$ was performed in two projections (anteroposterior and lateral view) covering $\mathrm{C} 1$ to $\mathrm{C} 7$. The central ray was focused to $\mathrm{C} 4$. The imaging parameters were: $20 \mathrm{mAs}, 100 \mathrm{~cm}$ FFD, and $81 \mathrm{kVp}$ for anteroposterior (AP) projection, and $85 \mathrm{kVp}$ for lateral projection. In addition, an open mouth odontoid process view projection was performed. In the AP projection patients were facing the X-ray tube and were

Table 1 Clinical and epidemiological characteristics of patient cohort $(n=79)$.

Tab. 1 Klinische und epidemiologische Charakteristika der Studiengruppe $(n=79)$.

\begin{tabular}{|llll|}
\hline & $\begin{array}{l}\text { patient popu- } \\
\text { lation (n=79) }\end{array}$ & $\begin{array}{l}\text { no injury } \\
\text { (n=71) }\end{array}$ & $\begin{array}{l}\text { fracture } \\
\text { (n=8) }\end{array}$ \\
\hline gender & $31(\mathrm{~m}) 48(\mathrm{f})$ & $31(\mathrm{~m}) 42(\mathrm{f})$ & $2(\mathrm{~m}) 6(\mathrm{f})$ \\
\hline average age & $60.3 \pm 25.6 y$ & $59.2 \pm 25.5 y$ & $69.9 \pm 26.3 y$ \\
\hline cervical pain & $23(24.0 \%)$ & $21 / 71(29.5 \%)$ & $2 / 8(25 \%)$ \\
\hline X-ray & & & \\
\hline op & $67(84.8 \%)$ & $63 / 71(88.7 \%)$ & $4 / 8(50.0 \%)$ \\
\hline ap & $79(100.0 \%)$ & $71 / 71(100.0 \%)$ & $8 / 8(100.0 \%)$ \\
\hline lat & $79(100.0 \%)$ & $71 / 71(100.0 \%)$ & $8 / 8(100.0 \%)$ \\
\hline MDCT & $79(90.0 \%)$ & $71 / 71(100 \%)$ & $8 / 8(100 \%)$ \\
\hline
\end{tabular}


positioned supine on the table bucky with arms at their sides. The midsagittal plane was aligned. The patients' knees were flexed up, with the soles of their feet flat on the table in order to reduce the curve of the lower back. In the left lateral position the arms were put to the front. The spine had to be in a position parallel to the table bucky. Positioning markers and gonadal shielding were used. To absorb excess scatter, radiation shielding was placed on the table.

\section{Imaging and measurement methods}

Measurement values were determined using a radiology information system - picture archiving and communication system (RIS-PACS system) (Centricity ${ }^{\mathrm{TM}}$ RIS-i 4.2 Plus, GE General Electric Company, USA).

\section{Odontoid process projection (op)}

3 parameters were determined in 67 patients receiving an additional odontoid process view:

For the right and left distance between the odontoid process and the lateral mass of $\mathrm{C} 1$, a horizontal line was drawn in the region in which the odontoid process showed the smallest diameter ( $\bullet$ Fig. 1a). Furthermore, two angles, one drawing a vertical line in the middle of the odontoid peg and a horizontal line from the right to left lateral mass of C2 ( $\bullet$ Fig. 1b) or the horizontal position $(\bullet$ Fig. 1c) were determined.

\section{Anterior-posterior (ap) projection}

Anterior-posterior projection scans were available in all patients undergoing X-ray scan after cervical spine trauma. Dens decentralization was determined measuring the right to left distance between central odontoid process and lateral mass of C1 ( $\bullet$ Fig. 2a).
Based on the method described above ( $\bullet$ Fig. 1), angles of the central vertical odontoid line and basis of C2 ( $\bullet$ Fig. $\mathbf{2 b}$ ) or the horizontal position ( $\bullet$ Fig. $\mathbf{2 c}$ ) were obtained.

\section{Lateral (lat) projection}

Lateral projections were conducted in all patients and were used for both evaluation of dorsal alignment of the vertebral body ( $\bullet$ Fig. 3a) and the determination of anterior and posterior atlantodental distance ( $\bullet$ Fig. 3b). Furthermore, the physiological position between C2 and C3 ( $\bullet$ Fig. 3c), angles of lateral odontoid vertical line and C2 basis ( $\bullet$ Fig. $\mathbf{3 d}$ ), and posterior line of odontoid process and C2 vertebral body ( $\bullet$ Fig. 3e) were analyzed.

\section{MDCT}

The MDCT examinations were performed on a 256-detector row computed tomography (CT) scanner (Brilliance iCT; Philips Healthcare, Best, The Netherlands). The images were obtained after a sagittal scout MDCT from C1 to C7 while the patients were positioned on the table and held their breath. The imaging parameters were: $120 \mathrm{kVp}, 250 \mathrm{mAs} /$ slice, pitch 0.985 and collimation $2 \mathrm{~mm} \times 128 \mathrm{~mm} \times 0.625 \mathrm{~mm}$. Midline sagittal and coronal images were reformatted from the axial datasets with a slice thickness of $3 \mathrm{~mm}$. The images in any case were viewed at a window level of 1000 Hounsfield units (HU) and a width of $2500 \mathrm{HU}$.

\section{Statistical analysis}

For statistical analysis a robust discriminatory power test was used. In this test, the discriminatory power D is calculated as a standardized mean difference (similar to a z-score). Statistical significance can be calculated from $\mathrm{D}$ by the degree of overlap (classification error) of two groups for a certain parameter distri-
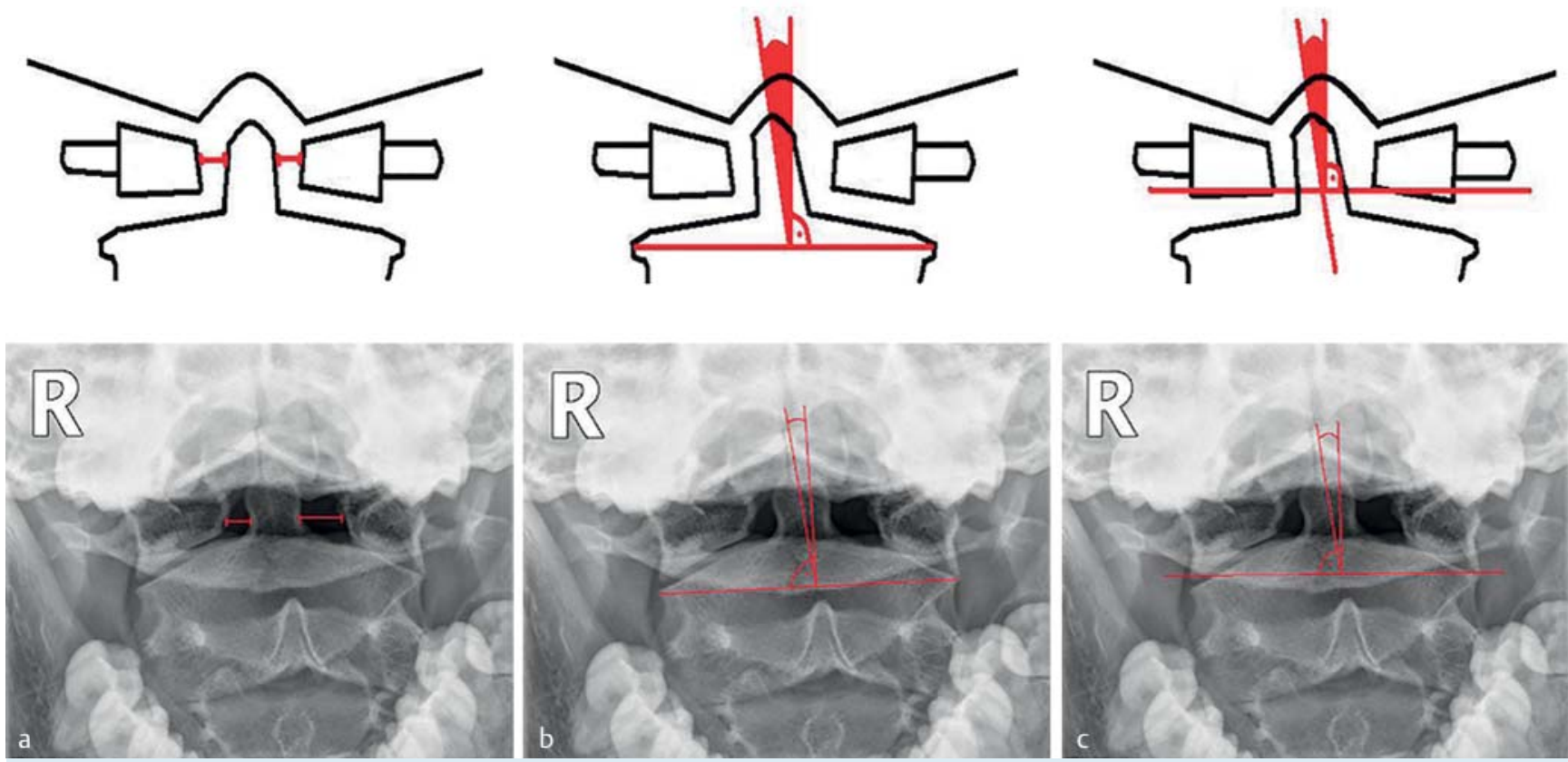

Fig. 1 Assessed parameters in odontoid process view. Above: diagrammed layout, below: X-ray pattern. a Right to left distance between odontoid process and lateral mass C 1 . b Angle of vertical odontoid line and horizontal line between right to left lateral mass C2. c Angle of vertical odontoid line and horizontal position.
Abb. 1 Untersuchte Parameter in der Dens Zielaufnahme. Oben: Schematische Skizze. Unten: Röntgenaufnahme. a Laterale distanz zwischen Dens axis und Massa lateralis C1. b Winkel der Dens axis Vertikalen zur horizontalen Linie zwischen der rechten und linken Massa lateralis C2. c Winkel der Dens axis Vertikalen zur Horizontalen. 

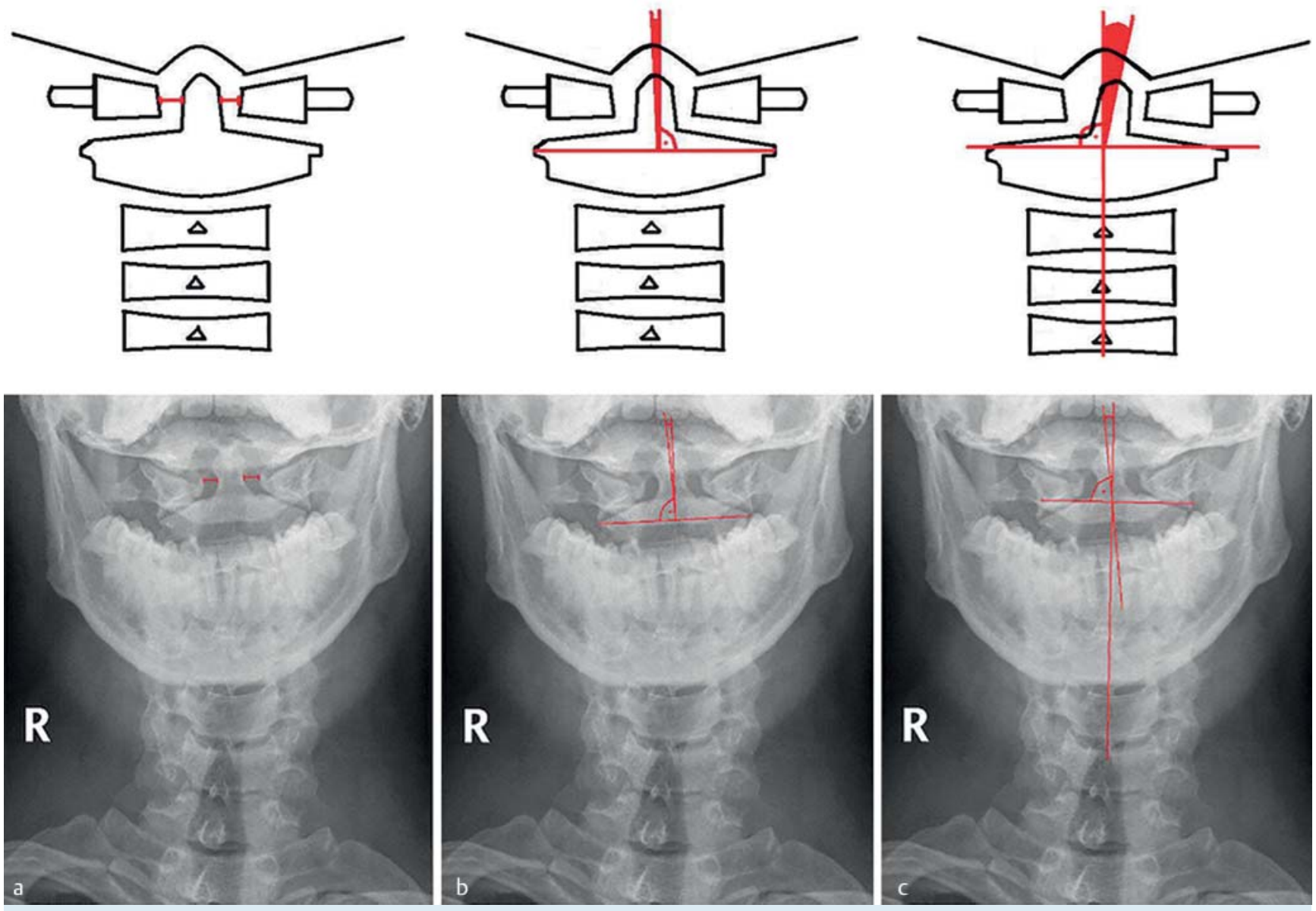

Fig. 2 Assessed parameters in anterior-posterior (ap) projection. Above: diagrammed layout, below: X-ray pattern. a Right to left distance between central odontoid process and lateral mass of $\mathbf{C} 1$. $\mathbf{b}$ Angle of vertical odontoid process line and basis of C2. c Angle of vertical odontoid process line and horizontal position.

Abb.2 Parameter in der ap Projektion. Oben: Schematische Skizze. Unten: Röntgenaufnahme. a Rechte und linke Distanz zwischen Dens axis und Massa lateralis C1. b Winkel der Dens axis Vertikalen und horizontaler Linie zur Basis von C2. c Winkel der Dens axis Vertikalen zur Horizontalen.

bution, but not necessarily with a common variance [23]. We also confirmed the test outcomes by the non-parametric Median test (Analyze-it Software Ltd, Leeds, UK), which checks the difference of two (or more) median values.

\section{Results}

$\nabla$

From 79 patients examined, 8 patients suffered from odontoid process fractures. In 71/79 patients no injury was detected. Only 2 patients ( $25 \%$ ) with diagnosed dens fracture admitted to cervical pain, compared to $21 / 71$ (29.5\%) patients without overt dens fracture. $67 / 79$ patients ( $84.8 \%$ ) received an open mouth odontoid process projection. Here, the average distance between odontoid process and lateral mass of $\mathrm{C} 1$ ( $\bullet$ Fig. 1a, 4a) was $0.49 \pm 0.13 \mathrm{~cm}$ in intact and $0.47 \pm 0.13 \mathrm{~cm}$ in fractured processes. The average angle value of the vertical odontoid line and horizontal line between right to left lateral mass ( $\bullet$ Fig. $\mathbf{1 b}, \mathbf{4 a}$ ) was $87.4 \pm 2.8^{\circ}$ versus $83.8 \pm 3.5^{\circ}$ and $86.7 \pm 2.7^{\circ}$ versus $86.5 \pm 1.9^{\circ}$ between the vertical odontoid process line and the horizontal ( $\bullet$ Fig. 1c, 4a). Anteroposterior projection scans were available in all 79 patients. The distance between the odontoid process and $\mathrm{C} 1$ vertebral body ( $\bullet$ Fig. 2a, 4b) was $0.47 \pm 0.11 \mathrm{~cm}$ in healthy versus $0.37 \pm 0.11 \mathrm{~cm}$ in fractures and the angles between the odontoid process and basis C1 ( $\bullet$ Fig. 2b, 4b) as well as the odontoid process and horizontal ( $\bullet$ Fig. $\mathbf{2 c}, \mathbf{4 b}$ ) were $87.8 \pm 2.6^{\circ}$ in healthy versus $86.1 \pm 2.2^{\circ}$ in fractures and $86.2 \pm 3.6^{\circ}$ versus $82.4 \pm 5.2^{\circ}$, respectively. Lateral projections were also taken in all 79 patients. Dorsal alignment ( $\bullet$ Fig. 3a) was found to be disrupted in $4 / 71$ healthy patients (6.0\%) versus 2 (25\%) patients with overt dens fracture. Physiological position (lateral angle between horizontal) of $\mathrm{C} 2 / 3$ ( $\bullet$ Fig. 3c) was normal in all patients. The atlantodental distance ( Fig. 3b, 4c) was $0.16 \pm 0.09 \mathrm{~cm}$ versus $0.12 \pm 0.09 \mathrm{~cm}$ and the angle between the posterior odontoid process vertical and posterior C2 vertebral body ( $\bullet$ Fig. 3e, $4 \mathrm{c}$ ) was $10.8 \pm 7.3^{\circ}$ versus $8.5 \pm 12.2^{\circ}$. The angle between the central odontoid vertical line and the $\mathrm{C} 2$ vertebral body horizontal ( $\bullet$ Fig. $3 \mathrm{~d}$ ) measured $88.5 \pm 6.2^{\circ}$ versus $88.6 \pm 6.3^{\circ}$ and deviated either in the frontal or dorsal direction. - Table 2 summarizes the radiographic measurement values obtained in all projections. In all measured parameters obtained in different projections, no significant changes were found between healthy patients and patients suffering odontoid fracture. 

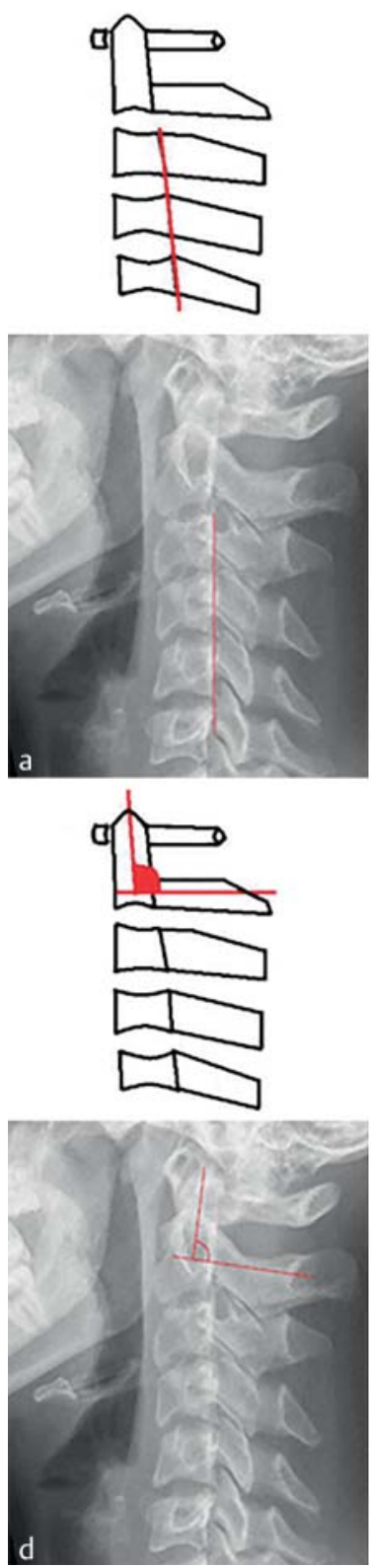
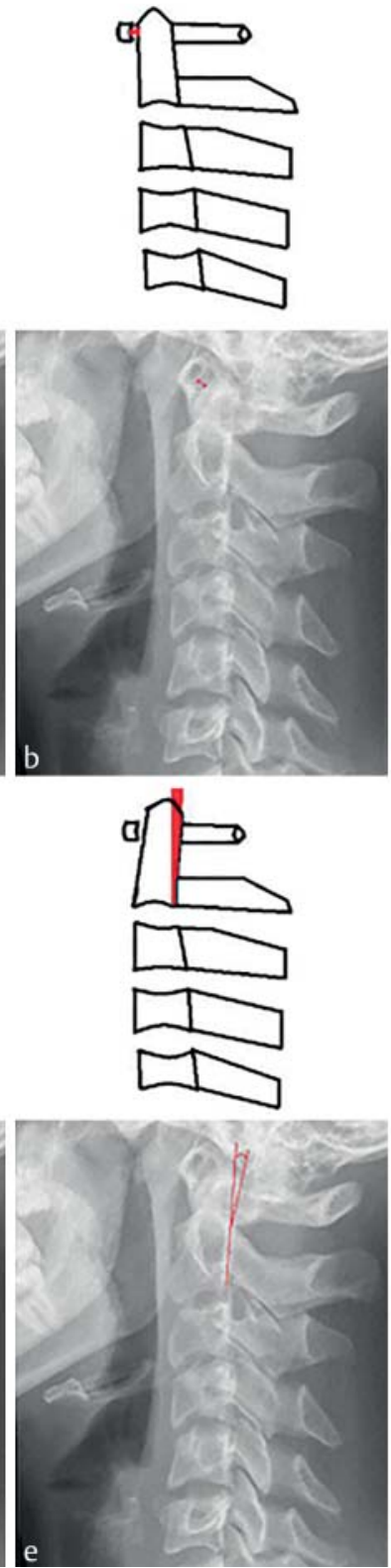
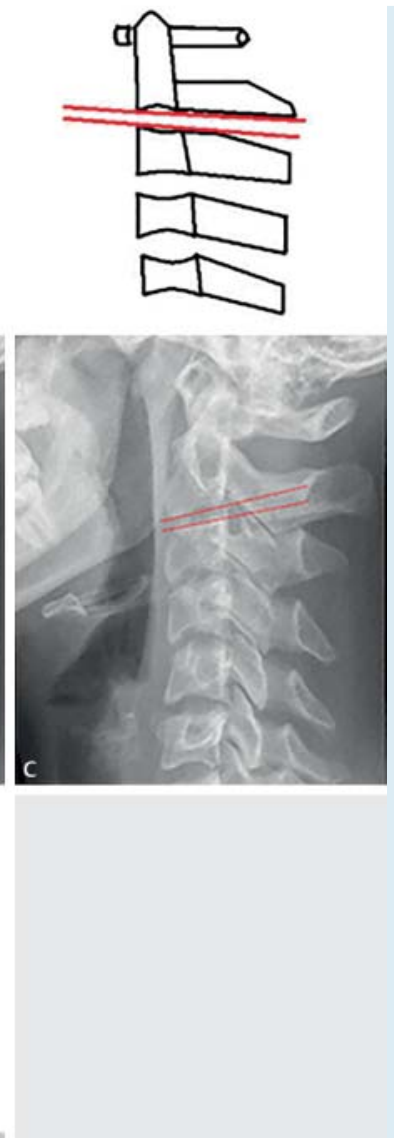

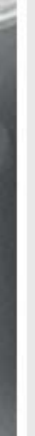

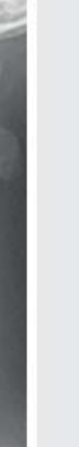

Table 2 Plain film radiographic measurement values in odontoid process, anteroposterior and lateral projection of healthy and fractured dens axis.

Tab. 2 Erhobene Messparameter des frakturierten versus intakten Dens axis im konventionellen Röntgen (Denszielaufnahme, a. p., und lat. Projektion).

\begin{tabular}{|c|c|c|c|}
\hline projection & $\begin{array}{l}\text { distance } \\
\text { Fig. 1a/4a }\end{array}$ & $\begin{array}{l}\text { angle } \\
\text { Fig. } 1 b / 4 a\end{array}$ & $\begin{array}{l}\text { angle } \\
\text { Fig. 1c/4c }\end{array}$ \\
\hline \multirow[t]{4}{*}{ op } & $0.49 \pm 0.13$ & $87.4 \pm 2.8$ & $86.7 \pm 2.7$ \\
\hline & $0.47 \pm 0.13$ & $83.8 \pm 3.5$ & $86.5 \pm 1.9$ \\
\hline & distance & angle & angle \\
\hline & Fig. 2a/4b & Fig. 2b/4b & Fig. $2 c / 4 c$ \\
\hline \multirow[t]{4}{*}{ ap } & $0.47 \pm 0.11$ & $87.8 \pm 2.6$ & $86.2 \pm 3.6$ \\
\hline & $0.37 \pm 0.11$ & $86.1 \pm 2.2$ & $82.4 \pm 5.2$ \\
\hline & distance & angle & angle \\
\hline & Fig. $3 b / 4 c$ & Fig. $3 \mathrm{~d}$ & Fig. $3 e / 4 c$ \\
\hline \multirow[t]{2}{*}{ lat } & $0.16 \pm 0.09$ & $88.5 \pm 6.2$ & $10.8 \pm 7.3$ \\
\hline & $0.12 \pm 0.09$ & $88.6 \pm 6.3$ & $8.5 \pm 12.2$ \\
\hline
\end{tabular}

no fracture fracture

\section{Discussion}

Cervical spine fractures occur in $1-3 \%$ of trauma cases and can cause devastating long-term physical impairment if underdiagnosed or misteated in the clinical course. Thus, reliable radiographic measurement standards are indispensable for the evaluation of cervical integrity, especially in light of the sometimes difficult analysis of the dens axis shape and articulation.

There is common agreement about certain radiographic signs associated with odontoid process fractures which can be easily detected and evaluated in conventional X-ray scans. These rediographic signs include the assessement of the anterior and posterior atlantodental interval (ADI and PADI) in the lateral projection, the lateral mass displacement in the open mouth odontoid process view, and the thickness and appearance of the prevertebral soft tissue (PVST) [16, 24, 25]. However, available guidelines, which evauated the sensitivity of plain film radiography after spinal trauma, recommend MDCT as the preferred imaging procedure [26]. To prevent the MDCT-associated disadvantages 


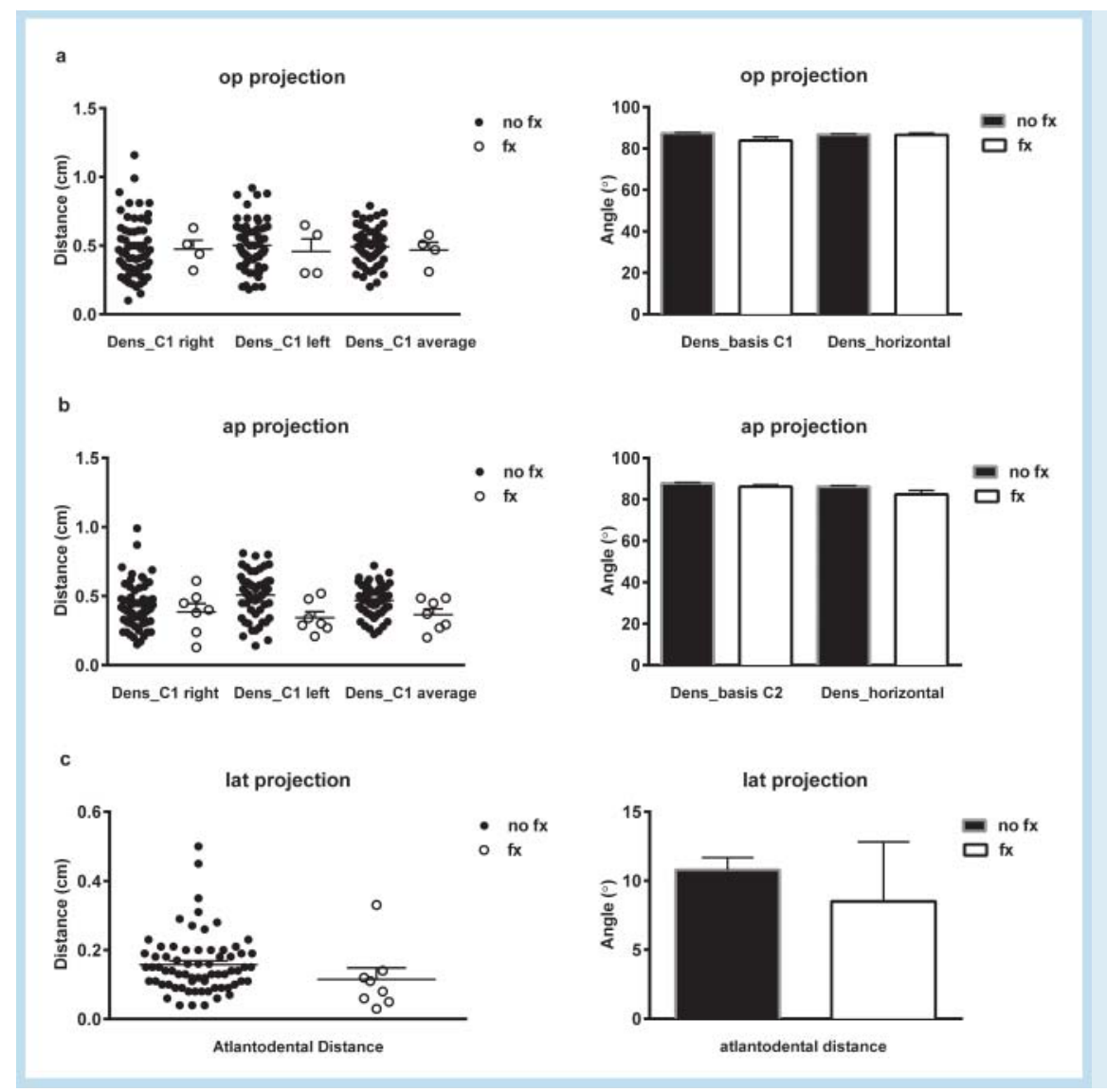

Fig. 4 Differences between measured parameters in healthy patients and patients presenting with dens fracture. a Odontoid process projection, distance dens_C1 and angle dens_basis $\mathrm{C} 1 /$ dens_horizontal. $\mathbf{b}$ ap projection, distance dens_C1 vertebral body and angle dens_basis C2/dens_horizontal. c Lateral projection, distance dens_basis and angle posterior dens_C2 vertical.

Abb.4 Unterschiede zwischen erhobenen Parametern in Gesunden versus Patienten mit Dens Fraktur. a Dens Zielaufnahme. Distanz Dens_C1, Winkel Dens_Basics C1 und Dens_Horizontale.

b Ap Projektion. Distanz Dens_C1, Winkel Dens_Basis C2 und Dens_Horizontale. $\mathbf{c}$ Laterale Projektion. Atlantodentale Distanz. Winkel Hinterkante Dens_C2.
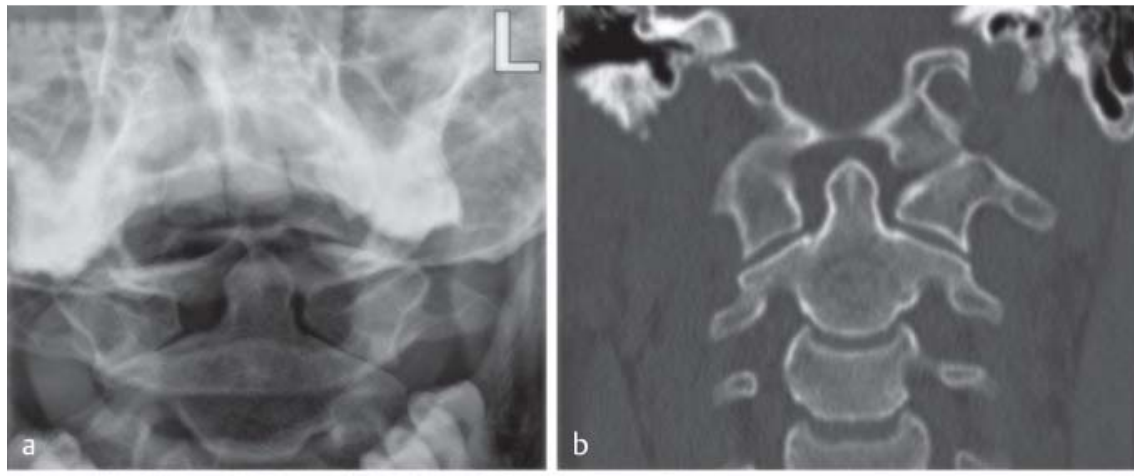

Fig. 5 a-d Lateralization of the odontoid peg in plain film radiography as sign of suspected fracture. Additionally performed MDCT scan proves physiological lateralization without fracture.

Abb.5 a-d Lateralisation des Dens axis in der Projektionsradiografie als indirektes Zeichen einer Densfraktur. Additives MDCT der Halswirbelsäule bestätigt die physiologische Dezentralisation ohne Frakturnachweis.
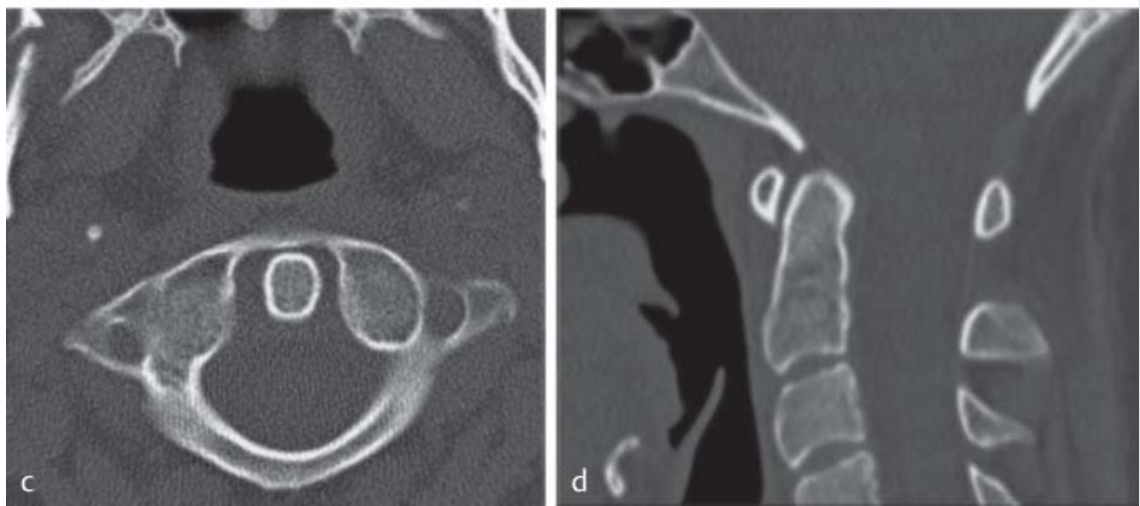

of higher radiation exposure and higher financial expenses, the aim of this study was to evaluate this conventional imaging method, based on standardized measurements in conventional $\mathrm{X}$-ray scans of the cervical spine. Our data indicate that there are no reliable differences on plain films of patients suffering from a dens axis fracture compared to patients with $\mathrm{C} 1 / \mathrm{C} 2$ integrity. These findings might be explained by the overt physiological distance and angle variation in healthy patients, contradicting the 
primary assumption of enhanced dens location variance in the interplay with $\mathrm{C} 1$ vertebral structures due to disrupture of dens axis alignment caused by fracture ( $\bullet$ Fig. 5 ). Furthermore intraand interobserver variability might additionally introduce measurement errors in conventional radiography as well as computed tomography [24]. Our results coincide with previous studies reporting a $65 \%$ to $90 \%$ (three view cervical spine series) sensitivity of plain radiography versus $98 \%$ to $100 \%$ of computed tomography for the screening of cervical spine injury [27 - 30]. Despite that, the higher susceptibility of plain radiography techniques for external confounding factors, especially in agitated or immobilized patients might additionally lower the quality and subsequent assessment of cervical structures $[9,31]$. The physiological anatomical variation of cervical structures, especially regarding the $\mathrm{C} 1$ / $\mathrm{C} 2$ articulation and interplay hampers the reliability of fixed measurement parameters in plain radiographic trauma series, thereby posing a risk of mis- or underdiagnosis of odontoid process fractures. Referring to the adavantages of MDCT in patients with suspected cervical spine fractures, such as the higher sensitivity and better assessability of the connected soft tissue, previous studies recommend replacement of plain films by MDCT to circumvent the potentially devastating consequences of undetected cervical spine fractures.

\section{Conclusion}

\section{$\nabla$}

Due to the wide variety of physiological odontoid process positions, X-ray-based metric analysis of deviations in cervical alignment and odontoid process angulation don't facilitate a definite diagnosis of cervical spine fractures. In patients with suspected injury of the cervical spine including the odontoid process, a dose-adapted MDCT scan of the cervical spine should be emphasized to prevent the risk of overlooking potentially harmful injuries.

\section{References}

1 Pratt H, Davies E, King L. Traumatic injuries of the $\mathrm{c} 1 / \mathrm{c} 2$ complex: computed tomographic imaging appearances. Curr Probl Diagn Radiol 2008; $37: 26-38$

2 Clark CR, White AA 3rd. Fractures of the dens. A multicenter study. J Bone Joint Surg Am 1985; 67: 1340-1348

3 Greene KA et al. Acute axis fractures. Analysis of management and outcome in 340 consecutive cases. Spine (Phila Pa 1976) 1997; 22: 1843 1852

4 Chutkan NB, King AG, Harris MB. Odontoid Fractures: Evaluation and Management. J Am Acad Orthop Surg 1997; 5: 199-204

5 Anderson $L D, D$ 'Alonzo RT. Fractures of the odontoid process of the axis. J Bone Joint Surg Am 1974; 56: 1663-1674

6 Elgafy $\mathrm{H}$ et al. Treatment of displaced type II odontoid fractures in elderly patients. Am J Orthop (Belle Mead NJ) 2009; 38: 410-416

7 Mulkens TH et al. Comparison of low-dose with standard-dose multidetector CT in cervical spine trauma. AJNR Am J Neuroradiol 2007; 28 : $1444-1450$
$8 \mathrm{Kim}$ DH et al. Early predictive value of supine and upright X-ray films of odontoid fractures treated with halo-vest immobilization. Spine J 2008; 8: $612-618$

9 Holmes JF, Akkinepalli R. Computed tomography versus plain radiography to screen for cervical spine injury: a meta-analysis. J Trauma 2005; 58: $902-905$

10 Davis JW et al. The etiology of missed cervical spine injuries. J Trauma 1993; 34: $342-346$

11 Reid $D C$ et al. Etiology and clinical course of missed spine fractures. J Trauma 1987; 27: 980-986

12 Gerrelts BD et al. Delayed diagnosis of cervical spine injuries. J Trauma 1991; 31: $1622-1626$

13 Albrecht RM et al. Evaluation of cervical spine in intensive care patients following blunt trauma. World J Surg 2001; 25: 1089-1096

14 Grossman MD et al. National survey of the incidence of cervical spine injury and approach to cervical spine clearance in U.S. trauma centers. J Trauma 1999; 47: 684-690

15 Harris $M B$ et al. Evaluation of the cervical spine in the polytrauma patient. Spine (Phila Pa 1976) 2000; 25: 2884-2891 discussion 2892

16 Bono CM et al. Measurement techniques for upper cervical spine injuries: consensus statement of the Spine Trauma Study Group. Spine (Phila Pa 1976) 2007; 32: 593-600

17 Heller JG, Carlson GD. Odontoid Fractures. In: Spine State of the Art Reviews. Philadelphia, Pennsylvania: Hanley and Belfust Inc; 1991

18 Platzer P et al. Clearing the cervical spine in critically injured patients: a comprehensive $\mathrm{C}$-spine protocol to avoid unnecessary delays in diagnosis. Eur Spine J 2006; 15: 1801 - 1810

19 Herzenberg JE et al. Emergency transport and positioning of young children who have an injury of the cervical spine. The standard backboard may be hazardous. J Bone Joint Surg Am 1989; 71: 15-22

20 Sun PP et al. Spectrum of occipitoatlantoaxial injury in young children. J Neurosurg 2000; 93: 28-39

21 Barrett TW et al. Injuries missed by limited computed tomographic imaging of patients with cervical spine injuries. Ann Emerg Med 2006; 47: 129-133

22 McCulloch PT et al. Helical computed tomography alone compared with plain radiographs with adjunct computed tomography to evaluate the cervical spine after high-energy trauma. J Bone Joint Surg Am 2005; 87: $2388-2394$

23 Penrose LS. Measurement of pleiotropic effects in phenylketonuria. Annals of eugenics 1951; $16: 134-141$

24 Bono CM et al. Observer variability of radiographic measurements of C2 (axis) fractures. Spine (Phila Pa 1976) 2010; 35: 1206 - 1210

25 Rojas CA et al. Normal thickness and appearance of the prevertebral soft tissues on multidetector CT. AJNR Am J Neuroradiol 2009; 30: $136-141$

26 Van Goethem JW et al. Imaging in spinal trauma. Eur Radiol 2005; 15 $582-590$

27 Harrison DE et al. Cobb method or Harrison posterior tangent method: which to choose for lateral cervical radiographic analysis. Spine (Phila Pa 1976) 2000; 25: 2072 - 2078

28 Radcliff KE et al. Comprehensive computed tomography assessment of the upper cervical anatomy: what is normal? Spine J 2010; 10: 219229

29 Widder S et al. Prospective evaluation of computed tomographic scanning for the spinal clearance of obtunded trauma patients: preliminary results. J Trauma 2004; 56: 1179-1184

30 Schleehauf $K$ et al. Computed tomography in the initial evaluation of the cervical spine. Ann Emerg Med 1989; 18: 815-817

31 Vandemark RM. Radiology of the cervical spine in trauma patients: practice pitfalls and recommendations for improving efficiency and communication. Am J Roentgenol Am J Roentgenol 1990; 155: 465 472 